\title{
KRAJEVNA IDENTITETA NA PRIMERU SREDNJE IN ZGORNJE GORENJSKE
}

\author{
Marijan M. Klemenčič*
}

Izvleček

UDK 911·373:314 (497.12 Gorenjska)

Krajevna identiteta kot najnižja stopnja regionalne identitete se krepi, čeprav je manj enotna in enoznačna kot v agrarni družbi.

Ključne besede: regionalna identiteta, lokalna identiteta, vaška skupnost, Gorenjska

LOCAL IDENTITY IN THE CASE OF CENTRAL AND

UPPER GORENJSKO

Abstract

UDC $911 \cdot 373: 314$ (497.12 Gorenjska)

Local identity as the lowest level of regional identity is growing stronger although it is less uniform and univocal than in the agrarian society.

Key words: Regional identity, Local identity, Village community, Gorenjsko

\section{UVOD}

V geografski strokovni literaturi je zelo slabo raziskana povezanost posameznika in družbene skupnosti z neposrednim okoljem. Do občutka povezanosti pride po dolgotrajnejšem sožitju neke skupnosti z okoljem, v katerega družba "odtisne" svojo podobo; ta slika zavisi od stopnje družbenega, gospodarskega, tehnološkega in kulturnega razvoja. Sčasoma se vzpostavi močno ravnotežje med pokrajino in družbo, ki živi v tem okolju.

Namen raziskave je bil, da bi se $v$ grobem osvetlila obsežna problematika odnosa prebivalcev do domačega okolja. Odprta področja in delovne hipoteze pa naj bi postavile solidne temelje za nadaljne empirične in teoretske raziskave tovrstne problematike.

Obravnavana so bila podeželska naselja; mesta zaradi velikosti in zapletene strukture zahtevajo drugačen pristop.

*Dr., doc., Oddelek za geografijo, Filozofska fakulteta Univerze v Ljubljani, Aškerčeva 2, 61000 Ljubljana, Slovenija 
Pri raziskavi so nas zanimale naslednje ključne tematike:

- krepitev (slabitev) lokalne skupnosti;

- odnos med domačini in priseljenci;

- lokacije v naselju, kjer se prebivalci srečujejo;

- krajevne posebnosti (znamenitosti);

- krajevni problemi;

- poimenovanje domače pokrajine in sosedstva.

\section{POTEK RAZISKAVE}

Večina dela je temeljila na pripravi vprašalnika, anketiranju in obdelavi vprašalnikov. V raziskavo sta bili vključeni dve skupini naselij: na Kranjskem polju in v Deželi. Obe območji sta po zadnji vojni doživeli velike spremembe; razlike med območjema so vezane na razlike v naravnih pogojih za kmetijstvo. Srednja Gorenjska je zaradi močnejše vloge kmetijstva kasneje doživela deagrarizacijo kot pa Zgornja Gorenjska, kjer so naravni pogoji za kmetovanje bistveno slabši. Ob tem je pomembno tudi to, da je na Srednjem Gorenjskem izrazita gospodarska dvojnost (močna prevlada industrijskega sektorja ob kmetijstvu), medtem ko ima na Zgornjem Gorenjskem pomembno vlogo terciarni sektor (turizem, trgovina).

Izvedeno je bilo obsežno anketiranje (485 anket) v 28 naseljih Zgornje in Srednje Gorenjske. Anketirali so študenti prvega letnika geografije $v$ okviru predmeta geografija naselij in študenti tretjega letnika geografije pri predmetu metodologija družbene geografije v maju leta 1993 in 1994.

Tabela 1: Osnovni demografski podatki vzorčnih naselij

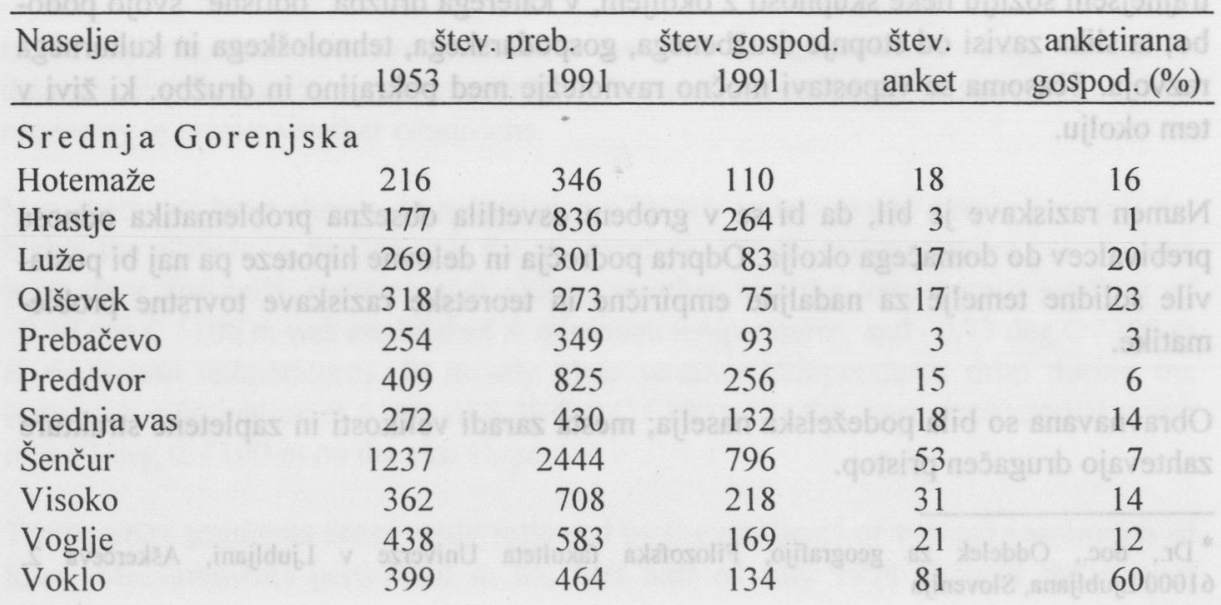


Zgornja Gorenjska

\begin{tabular}{lrrrrr} 
Begunje & 614 & 930 & 307 & 37 & 12 \\
Breg & 143 & 537 & 176 & 19 & 11 \\
Breznica & 165 & 425 & 137 & 16 & 12 \\
Doslovče & 135 & 131 & 42 & 14 & 33 \\
Dvorska vas & 159 & 179 & 53 & 3 & 6 \\
Hlebce & 157 & 239 & 745 & 8 & 11 \\
Hraše & 186 & 176 & 61 & 4 & 7 \\
Nova vas & 109 & 186 & 62 & 18 & 29 \\
Poljče & 191 & 211 & 67 & 18 & 27 \\
Rodine & 132 & 326 & 104 & 3 & 3 \\
Selo & 213 & 194 & 59 & 8 & 14 \\
Smokuč & 218 & 394 & 123 & 14 & 11 \\
Studenčice & 88 & 102 & 31 & 6 & 19 \\
Zabreznica & 317 & 484 & 152 & 3 & 2 \\
Zapuže & 133 & 303 & 101 & 18 & 18 \\
Zgoša & 285 & 359 & 109 & 2 & 2 \\
Žirovnica & 560 & 595 & 196 & 17 & 9 \\
\hline
\end{tabular}

Vir: Popis prebivalstva ... 1953, 1991, Zavod za statistiko.

Izbira anketirancev je bila naključna. $\mathrm{V}$ anketiranje je bilo $\mathrm{v}$ posameznih naseljih zajetih od $1 \%$ do $60 \%$ gospodinjstev; v dveh tretjinah naselij je bilo anketiranih vsaj $10 \%$ gospodinjstev.

\section{TEORETSKA IZHODIŠČA RAZISKAVE}

Vasi na Slovenskem so v zadnjih desetletjih doživele med drugim dve bistveni spremembi: razkroj stare, na tradicionalni (agrarni) družbi sloneče vaške skupnosti ter velike premestitve prebivalstva med naselji. Osnovni vzrok za te spremembe so velike družbenogeografske spremembe, ki jih je prinesla industrializacija.

Tradicionalna vas je lahko obstajala le, če so prebivalci sodelovali med seboj in tako ustvarili vaško skupnost. Pri urejanju skupnih vaških zadev so se vaščani namreč morali zanesti le náse.

Bistvena poteza sodobne družbe je zelo razčlenjena delitev dela. To, kar je nekdaj opravljala vaška skupnost, danes opravijo ustrezne službe (urejanje cest, kanalizacija, razsvetljava, telefon itd.). Iz istih razlogov se zmanjšujejo potrebe po sosedski pomoči. Rigg ugotavlja, da vas kot ideja, način družbene organiziranosti, kot osnova za življenje, ostaja zelo močna, tako v splošni (ljudski) predstavi, kot v raziskavah 
številnih znanstvenikov in praktikov. Vasi dojemamo kot družbene, proizvodne in upravne enote ter kot enote, s katerimi se prebivalci istovetijo (Rigg, 1994).

Značilnosti tradicionalne in sodobne vasi so naslednje (Rigg, 1994):

tradicionalna vas

- enakopravnost prebivalcev

- zadružnost (sodelovanje v skupno dobro)

- miroljubnost

- samozaupanje

- moralnost (podrejanje moralnim normam) sodobna vas

- neenakost prebivalcev

- individualizem

- nasilnost (tekmovalnost)

- odvisnost

- nemoralnost

V ostro nasprotje postavljenim oznakam bi lahko oporekali, česar se zaveda tudi avtor. Njegov namen je bil predvsem opozoriti na radikalne spremembe $v$ družbenih odnosih, ki vplivajo tudi na razvoj podeželskih naselij. Tudi v sodobnih družbah se mora namreč prej ali slej nasilnost in posamični egoizem podrediti skupnim interesom, pa čeprav $\mathrm{z}$ represivnimi sredstvi.

Že omenjeni Rigg se sprašuje, zakaj je ta problematika predmet geografskega proučevanja? Sam tudi odgovarja: zato, ker je interdisciplinarna, ker zadeva prostor in zgodovinski razvoj, nadzor nad ljudmi in območjem, dojemanjem preteklosti in sedanjosti, posebno še z vidika sprememb (Rigg, 1994).

Podobna vprašanja si postavljajo tudi v sociologiji. Do sedemdesetih let je vladala usmeritev, ki je izločala prostor iz socioloških preučevanj. V zadnjem času pa je prišlo do oblikovanja novega lokalizma (Strassoldo, Tessarin, 1990). V Sloveniji se med sociologi s tovrstno problematiko ukvarja posebno Mlinar. Ob povečevanju prostorske mobilnosti ljudi, materialnih dobrin, kapitala in informacij ugotavlja težnjo po destrukturiranju, fleksibilnosti ali celo fluidnosti ter prehodnem, kratkotrajnem značaju pojavnih oblik družbenega življenja. Ob takšni fluidnosti in kratkotrajnosti pa se stapljajo tudi oporne točke nekdanjih-kolektivnih in še zlasti teritorialnih identitet (Mlinar, 1994).

\section{KREPITEV (SLABITEV) VAŠKE SKUPNOSTI}

Na razvoj naselja vpliva tudi medsebojna povezanost prebivalcev, kar sociologi imenujejo socialna integracija; zanjo so pomembni skupni interesi in podoben način življenja posameznih članov skupnosti (Jałowiecki, 1972).

Družbenogospodarske spremembe v zadnjih desetletjih so povzročile močno preslojitev prebivalstva in pospešeno družbenogospodarsko selekcijo: čim bolj je naselje 
oddaljeno od zaposlitvenega in oskrbnega središča, tem večje je število odseljenih. Le-ti so običajno najbolj dinamičen in izobražen del prebivalstva.

Mlinar ugotavlja, da se je v zadnjih nekaj desetletjih v razvitejših območjih Slovenije že skoraj izgubila posebna identiteta podeželskega kmečkega okolja in kulture posameznih vaških skupnosti. S hitrim prodiranjem osebnega avtomobila, radia, televizije, časopisov ter podaljševanjem šolanja itd. je prihajalo do poenotenja mestne in podeželske kulture ter načina življenja nasploh (Mlinar, 1994).

Subjektivna ocena velike večine anketiranih je, da pripadnost vaški skupnosti slabi. Anketirani krivijo za to doseljence, različnost interesov (kmetje, nekmetje), sodoben način življenja itd. Vendar $v$ vsakem naselju del anketiranih čuti krepitev pripadnosti vaški skupnosti. Ta občutek ni le čustven odnos do kraja bivanja, ampak zelo konkreten odnos krajana do najbližjega okolja, ki se odraža prek soudeležbe pri urejanju skupnih zadev (ureditev javne razsvetljave, pločnikov, igrišč, organiziranja družabnih srečanj itd.). Posebno v nekaterih krajih je opazno povečevanje občutka pripadnosti vaški skupnosti prek oživljanja skupnih akcij. Nosilci teh akcij so lahko najrazličnejši, tako formalne organizacije (na primer gasilsko društvo), kot neformalne skupine (na primer skupine mladih družin).

Trdnosti oziroma slabosti vaške skupnosti bo pri nadaljnih raziskavah treba nameniti precej pozornosti, saj je to pomembna osnova za razvoj vsakega kraja.

\section{ODNOS MED DOMAČINI IN PRISELJENCI}

Integracijska sposobnost, to je sposobnost sprejemanja in vključevanja doseljencev v naselje, zavisi od stabilnosti in čvrstosti vaške skupnosti (Glück, Magel, 1993).

Večje število doseljencev $v$ naselju praviloma poruši ravnotežje $v$ odnosih med prebivalci. Poseben primer so naselja, na robu katerih so bile $\mathrm{v}$ kratkem času zgrajene večje stanovanjske soseske, tako da so nastala naselja - dvojčki. Družbenogospodarska sestava prebivalstva $v$ starejšem delu je pestra, $v$ novem delu pa izrazito homogena, zlasti $v$ demografskem pogledu.

Odnose med domačim in doseljenim prebivalstvom smo skušali ugotoviti z izjasnjevanjem anketiranih. Po pričakovanju so bili odgovori splošni in subjektivni. V povprečju prevladujejo pozitivni odgovori. Izstopa ocena prebivalcev starega dela vasi Smokuč, da skoraj ni stikov z doseljenci. To je razumljivo, če vemo, da gre za naselje, ki smo ga označili z naseljem - dvojčkom.

Vprašanje pritiska doseljencev na tradicionalno vaško skupnost je odločilno za organ- 
ski razvoj naselja. Postavlja se vprašanje, kje je prag deleža doseljencev, ki se lahko še vključijo $\mathrm{v}$ domačo skupnost, ne da bi bili narušeni ali celo porušeni odnosi med prebivalci $v$ naselju. Prav gotovo ne obstaja neka splošna vrednost, saj nanjo vplivajo številni, predvsem kakovostni dejavniki: značaj zazidave domov doseljencev (zgoščena zazidava ali razpršena med starimi domovi), družbenogeografska sestava doseljencev (homogena, heterogena), hitrost doseljevanja (kratkotrajno in intenzivno ali dolgotrajnejše) itd.

\section{MESTA SREČEVANJA VAŠČANOV}

Notranja povezanost kraja se izpolnjuje prek medsebojnega komuniciranja med prebivalci. Pri tem igrajo važno vlogo mesta v naselju, kjer se ljudje srečujejo. Predvsem iz leposlovne literature in ljudske pesmi so znana taka mesta (studenec ali potok, lipa itd.) in njihova materialna ter družbena funkcija (družabna srečanja, izmenjava novic). To so bila pomembna informacijska središča, živčni centri vaškega organizma. Že v tradicionalni družbi je bilo pogosto več takih središč, kjer je prišlo do druženja na stanovski osnovi (možje v gostilni, žene in dekleta ob vodnem viru itd.).

Mesta, kjer so se pred desetletji srečevali domačini, imajo običajno središčno lego v naselju, osrednji prostor, objekti ob njem pa simbolni pomen. Taka mesta so bila po navedbah anketiranih ob cerkvi, koritu, vaški lipi in gostilna). V prvih desetletjih 20. stoletja se je tem mestom pogosto pridružil prostor ob gasilskem domu.

Današnje "središče vasi" je odsev spremenjenih družbenogospodarskih odnosov v naseljih. Predvsem v manjših naseljih pogosto ostaja isto, kot nekoč: pri koritu (Doslovče, Smokuč), pri cerkvi (Olševek), ob vaški lipi (Voglje). Najstarejšim mestom srečevanja so se po navedbah anketiranih zelo uspešno priključili gasilski domovi (Prebačevo, Luže, Voklo, Hlebce, Begunje). V novejšem času se za del prebivalstva uveljavljajo mesta srečevanja, ki opravljajo funkcije koriščenja prostega časa: nogometno in teniško igrišče, picerija.

\section{KRAJEVNE ZNAMENITOSTI}

Odnos prebivalcev do domačega kraja se posebno močno odraža z odgovorom na vprašanje, na kaj (koga) so ponosni $\mathrm{v}$ domačem kraju. S tem vprašanjem smo želeli zaznati, s čim se prebivalci istovetijo; gre za opredeljevanje identitete kraja.

$\mathrm{Na}$ tako zastavljeno sprašanje se morajo prebivalci jasno in pozitivno opredeliti do domačega kraja. Ne preseneča, da so odgovori zelo različni celo pri prebivalcih istega naselja, pa tudi, da nekateri prebivalci niso ponosni na ničesar $v$ domačem kraju. Na 
drugi strani so nekateri anketiranci našteli več stvari (oseb), ki odlikujejo njihovo naselje.

Ponos na določeno odličnost (znamenitost) naselja je rezultat trdne navezanosti domačinov na naselje in hkrati znak, da $v$ njem vidijo določene vrednote in si jih tudi delijo.

Vrednote (posebnosti) naselja lahko delimo na konkretne (grad, cerkev), in splošne (lepa narava), pa tudi na materialne (kulturni dom, kapelica), personalne (pisatelji, pesniki), etične (prijateljstvo med ljudmi), simbolne (grb), itd.

Tudi $v$ tem primeru je vidna stopnja družbenogospodarskega razvoja in z njim povezanega širšega odnosa do sveta. Nekateri odgovori so prvi hip nenavadni ali celo smešni (mrliške vežice, lastni dom). Nekaj anketiranih se je izreklo za navidez majhne objekte (zvon, vodnjak). Vsekakor je iz odgovorov možno oceniti širino kulturnega obzorja prebivalcev: od ponosa na sadove fizičnega dela, do ponosa na pomembne osebe, ki so izšle iz njihovega kraja; vemo namreč, da pomembne osebe najteže dosežejo priznanje in čast pri domačem prebivalstvu.

Zanimivo je, da se večkrat precej razhajata zunanja in notranja predstava o kraju. Če je na primer nekdanji ansambel bratov Avsenik slovel ne le po Sloveniji, ampak tudi po dobršnem delu Evrope, tako da številni oboževalci iz tujine obiskujejo njihov dom v Begunjah, pa za domačine niso najpomembnejši identifikacijski znak. Po vzorčnih anketah sodeč sta pred njimi lepa narava in grad Kamen. Podobno je s tovarno Elan, ki se je uvrstila za Avsenike.

\section{KRAJEVNI PROBLEMI}

Občutek za probleme v naselju je lahko posledica zvračanja odgovornosti na druge, ali pa izostrenega posluha za dogajanja v domačem kraju. Poleg tega vsaka socialna skupina po svoje občuti probleme v naselju.

Tudi v tem primeru značaj problemov govori o stopnji družbenogospodarskega razvoja naselja. V vzorčnih naseljih so v ospredju komunalni problemi, ki govorijo o neurejenih osnovnih bivalnih pogojih: oskrba z vodo (Srednja vas), kanalizacija (Voglje, Breg), javna razsvetljava (Hotemaže, Preddvor), ureditev ceste skozi naselje (Voklo), povečanje prometne varnosti (Breznica, Nova vas).

Ob zagotovitvi osnovnih materialnih (infrastrukturnih) pogojev prebivalci začnejo v večji meri izpostavljati potrebe, ki so vezane na oskrbne dejavnosti (trgovine, razne obrti, zdravstveni dom, banka itd.), seveda v skladu z velikostjo naselja. 
Še višje stopnje so potrebe po zadovoljevanju rekreacijskih potreb (otroška in športna igrišča, bazeni, športne dvorane) in duhovnih potreb (kulturne prireditve, izboljšanje medsebojnih odnosov, možnosti druženja krajanov).

Vzorčna raziskava je pokazala, da so precejšne razlike med vrstami problemov, ki jih občutijo prebivalci naselij na Srednjem in Zgornjem Gorenjskem. Prebivalci naselij Srednje Gorenjske se predvsem ukvarjajo z osnovnimi, komunalnimi problemi, v manjši meri pa s "problemi višje stopnje". Povsem nasprotno je s prebivalci Zgornje Gorenjske, ki imajo po teh znakih sodeč višjo stopnjo kvalitete življenja.

Zaradi sorazmerno majhnega vzorca lahko marsikdo oporeka tem zaključkom. Vsekakor pa so ugotovitve dobro izhodišče za njihovo preverjanje in ovrednotenje s prihodnjimi raziskavami.

\section{POIMENOVANJE DOMAČE POKRAJINE IN SOSEDSTVA}

Z vprašanjem, kako prebivalci imenujejo domačo in kako sosednje pokrajine, smo želeli izpostaviti geografsko zelo pomemben dejavnik oblikovanja regionalne zavesti ali občutka pripadnosti določeni pokrajini. To področje nima le teoretičnega pomena (vsebina in obseg regij), pač pa tudi praktičnega (priprava predlogov upravne razdelitve).

Strokovna literatura o regionalni identiteti sicer ni ravno obsežna, je pa teoretično dobro obdelana. Posebej je treba izpostaviti francoske prispevke ter odličen pregled in ovrednotenje tovrstne literature, ki ga je napravil Paasi (1986).

Debarbieux (1989) glede poimenovanja pokrajinskih enot podaja naslednja spoznanja; poimenovati neko območje pomeni:

- označiti prostor (izpostavitev, individualizacija nekega kraja);

- dati smisel poimenovanemu kraju;

- dati prostoru ustroj;

- prispevati k uvajanju in obnavljanju predstav;

- izvajati simbolično prisvajanje;

- sporazumevanje, tudi med domačini.

Presenetljivo veliko zadreg anketiranih je bilo čutiti pri odgovarjanju na vprašanje, kako imenujemo pokrajino, $v$ kateri živijo. Vsaj $v$ tej prvi, uvodni fazi raziskave, se je pokazala razlika med pokrajinskim poimenovanjem, kot je uveljavljeno med domačini ter tistim, ki je uveljavljeno v šolskih učbenikih. 
Daleč najpomembnejši način pokrajinskega poimenovanja je poimenovanje po vaseh. To velja za domačo pokrajino, kot tudi za sosednje. V Deželi (le kdo uporablja to ime?) so nekateri govorili o Begunjskem kotu, živa pa je uporaba Kašarija in deloma Puntarija za vasi pod Pečmi.

Zdi se, da je glede razločevanja pokrajinskih enot podeželje ostalo v tradicionalnih okvirih, ko so bili prebivalci strogo navezani na domačo vas. Sosedstvo so predstavljale sosednje vasi. Možna pa je tudi drugačna razlaga: da so naselja tako pomembni pokrajinski elementi, da prevzamejo večino razpoznavnih znakov neke pokrajine.

\section{ZAKLJUČEK}

Regionalna identiteta postaja vse bolj upoštevana družbena kategorija. Njeno oblikovanje se začne na najnižji stopnji, v neposrednem življenjskem okolju posameznika, to je $v$ naselju. Raziskava je pokazala, da so naselja zelo pomembni identifikacijski objekti za domače prebivalce in za prebivalce $v$ bližnjem sosedstvu.

$\mathrm{Z}$ razpetostjo prebivalcev med kraje bivanja, zaposlitve, rekreacije, razvedrila, oskrbe se zmanjšuje potencial, namenjen oblikovanju občutka pripadnosti domačemu kraju (kraju bivanja). Potencial slabi tudi z vedno pogostejšimi selitvami prebivalstva, saj slabi vraščanje $v$ novo okolje. Kljub vsemu začetne raziskave kažejo, da se po nekaj desetletjih družbenogospodarske preobrazbe v Sloveniji razmere umirjajo ter da se obnavlja in krepi občutek krajevne (regionalne) pripadnosti.

\section{VIRI IN LITERATURA}

Debarbieux, B. 1989: Représentations da la haute montagne et nomination du territoire. V: Représenter l' espace. Anthropos, str. 95-107. Paris.

Glück, A.; Magel, H. 1993: Podeželje - vrt prihodnosti. Glavarjeva družba. Komenda. Jałowiecki, B. 1972: Miasto i społeczne procesy urbanizacji, PWN. Warszawa, Kraków.

Minnich, R. 1988: Tradicija ob boku modernizacije. Kulturna kontinuiteta in "dezagrarizacija" v vasi Ukve v Kanalski dolini, SLORI. Trst.

Mlinar, Z. 1994: Individuacija in globalizacija v prostoru, SAZU, Razred za zgodovinske in družbene vede, 35 . Ljubljana.

Mlinar, Z. 1990: Territorial identities: between individualization and globalization. V: Globality versus locality, Ur. Kuklinski A., University of Warszaw, str. 57-66. Warsaw.

Paasi, A. 1986: The institutionalization of regions: a theoretical framework for under- 
standing the emergence of regions and the constitution of regional identity. Fennia 164,1 , str. 105-146.

Popis prebivalstva in stanovanj 1953, 1991. Zavod za statistiko.

Rigg, J. 1994: Redefining the Village and Rural Life: Lessons from South East Asia.

The Geographical Journal 160, 2, str. 123-135.

Strassoldo, R.; Tessarin, N. 1990: Appartenenza locale e identità regionale: un' indagine sociologica. V: L' identità regionale. Atti del Symposium di Villa Vigoni Menaggio, str. 41-62. Trieste.

\section{LOCAL IDENTITY IN THE CASE OF CENTRAL UND UPPER GORENJSKO}

\section{Summary}

In the past decades, settlements in Slovenia underwent radical changes caused by the social transformation and the migrations of population. In the mid-fifties, a half of active population were peasants, while in the 90 's, their share amounted to one tenth only. In the same period, two thirds of Slovenian territory suffered moderate or heavy depopulation, while the rest of it underwent intense concentration of population.

The purpose of the study was to find out the extent and the way in which the people of certain settlements are connected among themselves and with the settlement as a whole, that is to say, the extent to which local identity is developed.

The following aspects were analysed:

- inter-relations between the locals and the immigrants;

- common meeting-place locations in a settlement;

- local points of interest;

- local problems;

- toponymy of the local and nearby areas.

The initial results of the study are presented. The investigation was based on the survey of 485 families in 28 rural settlements in the Ljubljana basin.

In the majority of settlements, the sense of belonging to the village community is awakening again through the revival of common activities which are managed by institutions or non-formal groups of people.

Locations in the settlements, where the residents used to meet times ago (by the church, under the central village linden tree, by the well) have partly changed (the fire brigade house, sports ground, etc.). 
Points of interest in the settlements, which the residents are proud of, are very diverse. We have divided them, on the one hand, into the actual (a castle, a church) and the general ones (beautiful nature), and, on the other hand, into the material ones (a house of culture, a chapel), the celebrities (writers, poets), the ethic ones (friendship), and the symbolic ones (a coat of arms).

A certain surprise for the investigators are the answers by the residents to the question how they call or name the local and the neighbouring areas. In most answers, the areas were determined by settlements. It has turned out that the settlements are so important elements of a landscape that they stand for the majority of identifying features of a certain area. 